tively charged a radiation and a second emanation, and so on until he changes cease to produce the usual effect on an electrometer. Whatever the nature of the radio-active material, the amount of radiation it enits in unit time is equal to $\lambda$ times the amount of radio-active element present, where $\lambda$ is a constant for each type of matter, and is unaffected by chemical and physical agencies.

Prof. Rutherford regards the process which goes on in radio-active substances as a gradual breaking up of the atoms of the substance, and this gradual disintegration as the cause of the radio-active properties. 'The electrically neutral atom of a radio-active substance throws off a positively charged body which constitutes the a radiation; what remains of the atom constitutes the emanation. This agai: throws off a positively charged body, and the process repeats itself until the positively charged bodies are exhausted, and the substance no longer possesses radio-active properties.

This disintegration theory fits all the known facts, but it involves the existence in the atom of a radio-active substance of a store of energy hitherto unsuspected, amounting in the case of radium to at least $10^{16}$ ergs per gram. This energy exists, according to Prof. Rutherford, as kinetic energy of motion of the atoms in closed paths with velocities comparable with that of light, and disintegration is the moving off at a tangent of one or more of the particles of an atom. If this is the case it seems probable that the atomic energy of elements not yet found to be non-radio-active is of the same order of magnitude, and may be set free by methods of which we are not yet cognisant.

In the discussion which followed Sir Oliver I.odge said the theory put forward by Rutherford seemed to him to be a valuable working hypothesis, very near, if not absolutely, the truth. It was supported by Larmor's electrical theory, according to which the atoms of matter should be unstable.

Lord Kelvin, in a letter communicated to the section, put forward another theory as to the nature of the processes going on in radio-active materials. According to it cach atom of matter has positive electricity distributed uniformly through its mass, and concentrated at one or more points, in general within it, atomic quantities of negative electricity, to which Lord Kelvin gives the name "electrions." A normal atom has the necessary number of electrions to neutralise the positive electricity associated with its matter. The $\alpha$ radiation consists of atoms of matter which have less than the normal number of electrions. When they move into matter they quickly pick up the negative charges necessary to render them neutral, and cease to be detected. The $\beta$ radiation consists of electrions thrown off during violent oscillations of the atoms of matter, and are readily absorbed by matter. The $\gamma$ radiation consists of vapour of the radio-active matter, e.g. radium, which would possess the penetrative power it is found to have if the Boscovichian forces between the atoms of radioactive matter and ordinary matter were small. The large amount of energy radiated is, according to this view, derived from without the atoms, where it exists in a form which we have not yet found a means of detecting.

Prof. Armstrong pointed out that, as the experiments of Rutherford and Soddy had been made on what was supposed to be radium bromide, the dissociation which they believed to be taking place might be of the compound and not of the element. He was disposed to regard Lord Kelvin's theory with favour.

Mr. Soddy thought ordinary chemical changes were excluded by the fact that the rate of production of the radiations was unaffected by chemical and physical conditions which greatly affected the former. The view Prof. Ruther. ford and he put forward was that at each stage of the process a new element was formed.

Prof. Dewar gave an account of the experiments on the effects of low temperature on the properties and spectrum of radium carried out partly in conjunction with Sir W. Crookes and recently communicated to the Royal Society.

Prof. Schuster thought the internal energy more probable than the absorption theory, and questioned whether the instability of the atoms predicted by electrical theory would account for the high velocities of the emanations. Ile was disposed to regard these high velocities as probably due to some cause not yet known.

Prof. Larmor agreed with Prof. Rutherford's theory, and pointed out that, just as atoms of matter must have size, or a half-size atom would still be an atom, so it may be that the atoms of electricity have size and configuration, and thus account for the complicated structure of the radium atom

Mr. Whetham directed attention to the still unexplained fact that the negatively charged emanation seemed to deposit more readily on negatively than on positively charged bodies, and Dr. Lowry, after recounting some experiments on the flash of light seen when certain substances are crushed, suggested that the emanation might be a modification of a constituent of the atmosphere, e.g. helium.

C. H. LEES.

\section{CHEMISTRY AT THE BRITISH ASSOCIATION}

THE Southport meeting of Section B proved to be one of the most successful held during recent years; the meetings were largely attended, and a keen interest was exhibited in the proceedings of the section. After the reading of the presidential address (Nature, p. 4 $\tau^{2}$ ), Prof. j. Campbell Brown described an apparatus for determining latent heats of evaporation, in which a known quantity of heat, generated electrically in a platinum wire, is absorbed in converting a liquid at its boiling point into vapour at the same temperature; very concordant results are obtained.

In a paper on some derivatives of fluorene, Miss Ida Smedley showed that whilst fluorenone $\stackrel{\mathrm{C}}{\mathrm{C}} \mathrm{C}_{6} \mathrm{H} \mathrm{H}_{4}>\mathrm{C}=\mathrm{O}$, is orange-red in colour, the corresponding sulphur derivative, thofluorenone, is intensely red; the radicle $>\mathrm{CS}$ has thus a greater tendency to produce colour than the carbonyl group. In a paper on the action of diastase on the starch granules of raw and malted barley, Mr. A. R. Ling showed that the starch derived from both raw and malted barley is dissolved. and hydrolysed by diastase at a temperature below its gelatinising point, and that the optical and reduction constants differ according to the sample of grain from which the starch is derived. Evidence was adduced in two other papers on the action of malt diastase on potato starch paste, one by $\mathrm{Mr}$. A. R. Ling and the other by $\mathrm{Mr}$. A. R. Ling and Mr. B. F. Davis, that when diastase is heated in aqueous solution at $60^{\circ}-70^{\circ}$ for a short time, the molecule of the enzyme becomes so changed that it no longer yields the same products when it acts on potato starch paste.

Dr. H. C. White described the chemical and physical characteristics of the so-called mad-stone, which, in accordance with a superstition current in the southern states of America, is used to detect and cure the bites of venomous snakes or rabid animals; the mad-stone is found to be a concretionary calculus from the gullet of the male deer, and is devoid of discriminative or curative powers.

Prof. E. A. Letts, Mr. R. F. Blake, and Mr. J. S. Totton read a paper on the reduction of nitrates by sewage, in which it was shown that, when potassium nitrate is added to the effluent from a septic tank, practically all the nitrogen is evolved in the free state or as nitric oxide; the oxygen of the nitrate is evolved as carbon dioxide.

A method for the separation of cobalt from nickel and for the volumetric determination of cobalt was described by Mr. R. L. Taylor; it is based on the fact that cobalt is precipitated quantitatively as a black oxide from neutral solutions by barium or calcium carbonate in presence of bromine water. The black oxide has the composition $\mathrm{Co}_{2} \mathrm{O}_{14}$ or $\mathrm{Co}_{7} \mathrm{O}_{11}$

Prof. J. Dewar, F.R.S., contributed a description of the more recent results obtained from his investigations at low temperatures; he described the methods by which he has succeeded in determining the densities of solid hydrogen nitrogen, and oxygen, the methods of producing solid hydrogen and nitrogen, and the methods by which he has been able to determine the latent heats, specific heats, and the coefficient of expansion of liquid hydrogen.

A paper on the application of low temperatures to the study of biological problems, by Dr. Allan Macfadyen, is printed in another part of the present issue (p. 608).

Mr. J. Hübner and Prof. W. J. Pope, F.R.S., gave a paper on the cause of the lustre produced on mercerising 
cotton under tension, which was illustrated by photographs in natural colours; the lustre of mercerised cotton is proved to be due to a corkscrew-like structure of the mercerised fibre brought about by a simultaneous swelling, shrinking and untwisting which attends the immersion in caustic soda.

Sir H. Roscoe, F.R.S., in presenting the report of the committee on duty-free alcohol, explained the conditions under which the Board of Inland Revenue are now prepared to allow the use of duty-free alcohol for the purposes of research work.

Prof. G. von Georgievics, in a paper on the theory of dyeing, argued strongly in favour of the mechanical as opposed to the chemical theory of dyeing, and claimed that the experimental work upon which the chemical theory is based is erroneous.

In opening a discussion on the general subject of combustion by a paper on the slow combustion of methane and ethane, I)r. W. A. Bone pointed out that his own experimental work showed that, in the combustion of methane, a primary oxidation to formaldehyde and steam occurs, followed by rapid oxidation of the formaldehyde to carbon monoxide, carbon dioxide and steam; in the burning of ethane both acetaldehyde and formaldehyde are formed as intermediate products.

In a prelininary note on some electric furnace reactions under high gaseous pressures, Messrs. J. E. Petavel and R. S. Hutton gavé an account of work carried out in an enclosed electric furnace constructed to work with gaseous pressures up to 200 atmospheres. The reactions at present under investigation include the direct reduction of alumina by carbon, the formation of calcium carbide and of graphite, and the production of nitric acid and of cyanogen compounds.

In a paper on the atomic latent heats of fusion of the metals considered from the kinetic standpoint, $\mathrm{Mr}$. $\mathrm{H}$. Crompton showed that, if in the solidification of a liquid energy is lost solely in bringing moving monatomic molecules to rest, a constant can be deduced in a very simple manner fron the latent heat of fusion; approximately the theoretical value is obtained for this constant with many of the metals, but not with gallium and bismuth.

Dr. E. P. Perman brought forward a number of results which he has obtained concerning the influence of small quantities of water in bringing about chemical reaction between salts; he investigated more particularly the action of potassium iodide upon salts of lead and mercury. In a paper on the constitution of disaccharides, Prof. Purdie, F.R.S., and Dr. J. C. Irvine described the methylation of cane-sugar and maltose; from experiments on the hydrolysis of the products of methylation they deduced evidence substantiating the constitutions attributed by Fischer to these two disaccharides.

Amongst other papers read in the section may be noted the following :-Stead's recent experiments on the causes and prevention of brittleness in steel, by Prof. T. Turner; the colour of iodides, by $\mathrm{Mr}$. W. Ackroyd; on essential oils, by Dr. O. Silberrad; the cholesterol group, by Dr. R. H. Pickard; on acridines, by Prof. A. Senier sur le spectre de self-induction du silicium et ses comparaisons astronomiques, by $\mathrm{M}$. le Comte $\mathrm{A}$. de Gramont fluorescence as related to the constitution of organic substances, by Dr. J. T. Hewitt; freezing point curves of binary mixtures, by Dr. J. C. Philip; mutarotation in re. lation to the lactonic structure of glucose, by Dr. E. F. Aimstrong; the synthesis of glucosides, the preparation of oximido-compounds and the action of oxides of nitrogen on oximido-compounds, by $\mathrm{Mr}$. W. S. Mills; further investigations of the approximate estimation of minute quantities of arsenic in food, by Mr. W. Thomson.

GEOLOGY AT THE BRITISH ASSOCIATION. $T$ HE programme of the geological section of the British Association is usually more or less affected by the geological character of the country around the place of meeting, and this was the case in the present year, though the geology of Southport cannot compare in interest with that of Belfast, Glasgow, or other recent meeting places.

Mr. J. Lomas (Geology of the country around Southport) explained that the solid rock, Keuper and Bunter, is for the most part below sea-level, and only reaches the surface NO. 1773 , vOL. 68 ] in a few places where it projects through the thick covering of Drift. The Drift is mainly Boulder-clay with an undulating surface, on which are found a number of lakedeposits, left by lakes or meres now partially or wholly drained.

One of these, Martin Mere, was visited by most of the geologists present, and was the subject of a paper by $\mathrm{Mr}$. Harold Brodrick. Upon the Boulder-clay there is a bed of grey clay, which may be of either lacustrine or estuarine origin, and on it grew a forest of oak and Scotch fir. Numbers of trunks of the trees still remain, and Mr. Brodrick remarked that they have usually fallen in a north-east direction. These tree trunks are buried in a bed of peat, which is in places as much as 19 feet thick, and many dug. out canoes have been found in this peat.

The "submerged forest" at Leasowe, in Cheshire, is the remains of a similar mere which has been cut through by the sea, and the peat and tree trunks are now found on the coast below the level of high water. The question whether this points to a depression of the surface of the land was discussed, but the speakers hesitated to give any definite opinion.

$\mathrm{Mr}$. Whitaker read the report of a committee appointed by the council of the Association to record observations on changes in the sea coast of the United Kingdom, and though there was no reference to Southport in the report, its reading was followed by considerable discussion. At Southport itself the land is gaining on the sea, and $\mathrm{Mr}$. Lomas considers this to be due to the large amount of material brought down by the River Ribble. The sand dunes on the coast are, he believes, also due to material brought down by the river, which, drying at low water, is blown inland by the prevailing south-west wind. He remarked that sand dunes are usually found at and near the mouth of a fairly large river.

The question of coast changes was also discussed in a paper on a raised beach in County Cork by Messrs. Muff and Wright, of the Geological Survey. The beach deposits rest upon a platform of solid rock which is some 7 to 12 feet above the corresponding part of the present shore, and the beach deposits are covered by a thick bed of Boulderclay, showing that they are of early Glacial, if not of preGlacial, age. This is almost an exact counterpart of the raised beach in Gower, South Wales, which was described by $\mathrm{Mr}$. R. H. Tiddeman in a paper read before Section C of the British Association at Bradford in 1900.

$\mathrm{Mr}$. Lamplugh (Land shells in the infra-Glacial chalkrubble at Sewerby, near Bridlington) directed attention to the similarity of these raised beaches to that at Sewerby in Yorkshire. There we find (I) a beach deposit, a few feet above the present high-water mark, banked against an old chalk cliff; (2) a bed of land wash; (3) a bed of blown sand; and upon it (4) a bed of chalk-rubble, in which $\mathrm{Mr}$. Lamplugh has found many specimens of Pupa muscorum, a land shell. Consequently the bed is a land wash corresponding to the "Head" of Cork and Gower. The author found this bed on the foreshore at Sewerby, showing that when it was formed the sea stood at a lower level than at the time of the beach deposits. This land wash is underneath all the Glacial Drifts of the Yorkshire coast.

In the discussion which followed the reading of these papers, it was suggested that the raised beaches may be due to an alteration in the level of the sea rather than to earth-movement. $\mathrm{Mr}$. Clement Reid, however, remarked that, though the old sea beaches in Cork, Gower, and Yorkshire are about the same height above the present sealevel, there is at Penzance a well-marked notch in the rock at 65 feet above the sea, and in Sussex there is evidence of a sea-surface not only a few feet above the sea at Selsea but also as much as 135 feet above the sea in Goodwood Park.

The relations of an estuarine deposit at Kirmington, in Lincolnshire, to the Glacial Drift was the subject of the report of a committee appointed at Belfast last year. The Kirmington Drift deposits are known to rest upon chalk, though the chaik has not yet been reached. A silty sand and chalk-rubble ( 1 ) is the lowest bed at present examined; upon it rests (2) a purple clay, no doubt a Boulder-clay, 12 feet thick; and above that (3) sand and chalky gravel 12 feet. Upon this (4) a thin fresh-water bed has now been found, and (5) a clay with estuarine shells, the whole being under (6) a second bed of Boulder-clay. The estuarine bed 